\title{
Statistical Analysis for Change Detection and Trend Assessment in Climatological Parameters
}

\author{
R. K. Jaiswal ${ }^{1}$ • A. K. Lohani ${ }^{2}$ • H. L. Tiwari $^{3}$
}

Received: 28 December 2014 / Accepted: 17 August 2015 /Published online: 27 August 2015

(C) Springer International Publishing Switzerland 2015

\begin{abstract}
Considering the importance of climatic variability on availability of water, irrigation demand, crop yield and other areas of life, an assessment of change detection and trend on monthly, seasonal and annual historical series of different climatic variables of Raipur, a capital city of newly created Chhattisgarh state of India, have been carried out. The change detection analysis has been conceded using Pettitt's test, von Neumann ratio test, Buishand's range test and standard normal homogeneity (SNH) test, while non-parametric tests including linear regression, Mann-Kendall and Spearman rho tests have been applied for trend analysis. The annual series of minimum temperature, wind speed, sunshine hour showed significant change points, while evaporation indicated a doubtful case and maximum temperature confirmed the homogeneity at $95 \%$ confidence level. The change point analysis results of meteorological variables indicated different change points from year 1990 to 2000, with maximum change points in and around 1995. This was due to the industrialization and urbanization in this period as this city was selected as capital of Chhattisgarh state. Based on the results of change point analysis and development scenarios in and around Raipur city, trend analysis was applied for three different time periods namely: P-1 from 1971 to 1995, P-2 from 1986 to 2012, and P-3 the whole series from 1971 to 2012. The significant rising trend in the summer and rainy months in case of minimum temperature, and the winter months in case of maximum temperature during the periods P-2 and P-3 may affect water availability and water demands in the region. The relative humidity showed a significant rising trend in few summer and rainy months series of all three periods under investigation, while sunshine hours and evaporation indicated random distribution prior to 1995 (P-1), but a significant falling trend in few winter months and annual series during period P-3. Although the annual minimum, maximum temperatures and relative humidity showed a rising trend, the falling trend of pan evaporation
\end{abstract}

R. K. Jaiswal

rkjaiswal_sagar@yahoo.co.in

1 National Institute of Hydrology, RC Bhopal, WALMI Campus, Kolar Road, Bhopal, MP, India

2 National Institute of Hydrology, Jal Vigyan Bhavan, Roorkee, Uttarakhand, India

3 Maulana Azad National Institute of Technology, Bhopal, MP, India 
may be due to strong declining trends in wind speed and falling trend in sunshine hour series on a long term basis.

Keywords Climate change $\cdot$ Climatic variables $\cdot$ Trend analysis $\cdot$ Change point $\cdot$ Significance level

\section{Introduction}

Various reports of the Intergovernmental Panel on Climate Change (IPCC) predict that increased emissions of greenhouse gases after worldwide industrialization due to large scale combustion of fossil fuels, human intervention and landuse change will result in increase in global temperature. Intergovernmental Panel on Climate Change (2002) observed that natural forces and human activities have significant contributions to the alteration of climatic patterns, i.e., increase of land and ocean surface temperature, change in spatial and temporal patterns of precipitation, increase of frequency of extreme events, sea level rise and intensification of El Nino. An average increase of $0.6{ }^{\circ} \mathrm{C}\left(0.4\right.$ to $\left.0.8^{\circ} \mathrm{C}\right)$ in the global temperature during the period of 1901 to 2001 indicated warming of Earth in the last many decades (Intergovernmental Panel on Climate Change 2007). The analysis of historical series of mean monthly and annual temperatures in different parts of the globe suggested that 2005 was the warmest year in the historical series. Other warm years in the series that have occurred after 1990 were 1998, 2003, 2002, 2004, 2001, 1999, 1995, 1990, 1997, 1991 and 2000. The rising annual temperature was found due to temperature anomalies for the months of June, July and August in both hemispheres (Lugina et al. 2006).

The change in trends of different climate variables can be quantified by application of global circulation models (GCMs)/regional circulation models (RCMs) or statistical analysis of historical data. Shrestha et al. (2014) used downscaled output of A2 and B2 scenarios of HadCM3 GCM model data to predict climate impact on hydropower in Kulekhani project in Nepal. The statistical trend detection in climatic variables and precipitation time series is one of the interesting research areas in climatology and hydrology as it impacts spatial and temporal distribution of water availability across the globe. The crop yield, which largely depends on variation of atmospheric temperature, confirmed a reduction of 15-35\% in Africa and west Asia and 25-35\% in the Middle East due to increase of temperature just 2 to $4{ }^{\circ} \mathrm{C}$ (FAO 2001). Schaefer and Domroes (2009) analyzed mean daily temperature of many stations in Japan using Gaussian binomial low-pass filter, linear regression and non-parametric, non-linear trend suggested by MANN (MANN's Q) and observed an increasing trend in annual temperature from $0.35^{\circ} \mathrm{C}$ (Hakodata) to $2.93{ }^{\circ} \mathrm{C}$ (Tokyo) over the period of 100 years (1991-2000). Japan as a whole indicated a warming climate over the entire period of observations (1991-2000, 1951-2000 and 1976-2001). It is worthwhile to mention that the quantum change of different climatic variables, including temperature and precipitation, are not globally uniform, and large scale spatial and temporal variation may exist in climatically diverse regions (Yue and Hashino 2003). Apart from the rainfall and temperature factors, wind velocity and relative humidity also affects the livestock and agriculture sector (Sivakumar et al. 2012a; Ravindran et al. 2000). Several researchers all over the world have investigated historical times series of temperature, precipitation and runoff for statistical trend identification and change point detection to understand impact of possible climate change and impact of industrialization and anthropogenic 
activities (Serra et al. 2001; Zer Lin et al. 2005; Smadi 2006; Smadi and Zghoul 2006; Katiraie et al. 2007; Boroujerdy 2008; Ghahraman and Taghvaeian 2008; Sabohi 2009; Shirgholami and Ghahraman 2009; Al Buhairi 2010; Karpouzos et al. 2010; Sun et al. 2010; Roshan et al. 2011; Croitoru et al. 2012; Bavani et al. 2012 etc.). In other scientific fields also, time series modeling and change point detection in particular has become an active area of research because of fast changing scenarios (Aderson 1994; Baseville and Nikiforov 1993; Chen and Gupta 2001; Silvestrini and Veredas 2008 etc.).

The parametric or non-parametric method under statistical approach is used to detect if either a data of a given set follows a distribution or has a trend on a fixed level of significance. Various non-parametric tests, including Mann-Kendall test and Pettit's test, are widely used to detect trend and change point in historical series of climatic and hydrological variables. Fu et al. (2007) studied the impact of climatic variability on streamflows, temperature and precipitation in the Yellow River basin, and found that climate variability had a significant impact on streamflow and it was sensitive to both precipitation and temperature. Jaiswal et al.(2008) analyzed evaporation and rainfall data for the period of 1971 to 2000 for 58 well distributed stations over India for trends of these two parameters in the country as a whole and for individual stations in annual, winter, summer, monsoon and post-monsoon periods at $95 \%$ level of confidence. They observed that the evaporation had significantly decreased in all seasons while there was no significant trend in rainfall. Gao et al. (2009) analyzed annual streamflow and sediment discharge in the Wuding River, and observed a significant decreasing trend. Eslamian et al. (2009) assessed the impact of climate change on wind speed of twenty two stations in Iran with the help of frequency analysis coupled with heterogeneity, to understand the wind behavior in time.

Salarijazi et al. (2012) have analyzed streamflow series of the annual maximum, annual minimum and annual mean in Ahvaz hydrometric station, as representative of the Karun watershed, to determine the change point using Pettitt's test, and performed trend analysis with the help of Mann-Kendall test. The Pettitt's test did not detect any change point in these series, but the Mann-Kendall test showed that there was an increasing trend. Jain and Kumar (2012) reviewed several studies on trend analysis of temperature, rainfall and rainy days in India and observed that significant trend was determined frequently by Mann-Kendall test and its magnitude by Sen's non-parametric slope estimator. Sivakumar et al. (2012b) carried out trend analysis of meteorological parameters including average temperature, relative humidity, wind speed and rainfall for the period of 2001 to 2007 in northeastern zone of Tamilnadu (India) using cluster analysis, and found that all the parameters varied with year and the maximum changes were observed during 2005 and 2004 followed by 2007. Yue et al. (2002) analyzed daily flow data of twenty pristine basins in Canada using Mann-Kendall and Spearman's rho test for assessment of significant trend and found that higher number of sites confirmed a significant falling trend. Karmeshu (2012) applied Mann-Kendall test statistic for analysis and detection of trends in meteorological data and precipitation of nine states in the USA from 1900 to 2011. All the states of USA confirmed a significant increasing trend for precipitation and temperature series, except Maine where both the series were found randomly distributed, along with Pennsylvania and New Hampshire which showed no trend for temperature and precipitation, respectively. 
In order to understand the magnitude and direction of underlying trends, many techniques have been proposed in the past, including t-tests (e.g., Staudt et al. 2007; Marengo and Camargo 2008), Mann-Whitney and Pettitt's tests (e.g., Mauget 2003; Fealy and Sweeney 2005; Yu et al. 2006), linear and piecewise linear regression (e.g., Tomé and Miranda 2004; Portnyagin et al. 2006; Su et al. 2006), cumulative sum analysis (e.g., Fealy and Sweeney 2005; Levin 2011), hierarchical Bayesian change point analysis (e.g., Tu et al. 2009), Markov chain Monte Carlo methods (e.g., Elsner et al. 2004), reversible jump Markov chain Monte Carlo simulation (e.g., Zhao and Chu 2010), standard normal homogeneity test (e.g., Gonzalez-Rouco et al. 2001; Winingaard et al. 2003; Stepanek et al. 2009), and nonparametric regression (e.g., Bates et al. 2010).

In the presentstudy, the statistical methods of trend detection and change point analysis have been used for climatic parameters including maximum temperature, minimum temperature, wind speed, humidity, sunshine hours and evaporation of Raipur city of Chhattisgarh state of India, which is transforming to the industrial hub in the region, due to large scale industries and human intervention because, since 2000 , it is the capital of a newly born state.

\section{Study Area and Data Used}

Raipur, the capital of Chhattisgarh of India has been selected for study of statistical change and trend detection in meteorological variables due to climate change and/or human induced intervention due to rapid growth of population, urbanization and industrialization. Raipur District is situated in the fertile plains of Chhattisgarh region situated between $22^{\circ} 33^{\prime} \mathrm{N}$ to $21^{\circ} 14^{\prime} \mathrm{N}$ latitude and $82^{\circ} 6^{\prime} \mathrm{E}$ to $81^{\circ} 38^{\prime} \mathrm{E}$ longitude (Fig. 1). The district lies in the south eastern part of upper Mahanadi valley with hilly regions in the south and east. River Mahanadi, one of the major rivers of the Chhattisgarh state along with its tributaries, viz. river Kharun, Sendur, Pairy, Joan and Seonath, passes the district to make it fertile and productive. The population of Raipur district was $3,016,960$ in 2001 , increased to $4,063,872$ in year 2011 at a rate of $34.7 \%$ due to fast development and industrialization. Meteorological data, including monthly minimum and maximum temperature, wind speed, relative humidity from 1971 to 2012, sunshine hour and pan evaporation data from 1981 to 2012 collected from Indira Gandhi Agriculture University, Raipur (Chhattisgarh), India, were used in the analysis. The statistical information regarding various meteorological variables is presented in Table 1.

\section{Methodology}

The methodology applied for the study includes computation of mean monthly values, statistical analysis, application of trend detection and change point analysis for different climatic variables using historical data of Raipur. In the analysis, different statistical tests were applied on maximum temperature, minimum temperature, relative humidity, wind speed, sunshine hour and evaporation on monthly, annual and seasonal (summer, rainy and winter) basis for determination of change point analysis and detection of trend for identification of climate change impact. Different statistical tests applied on meteorological parameters are described here. 


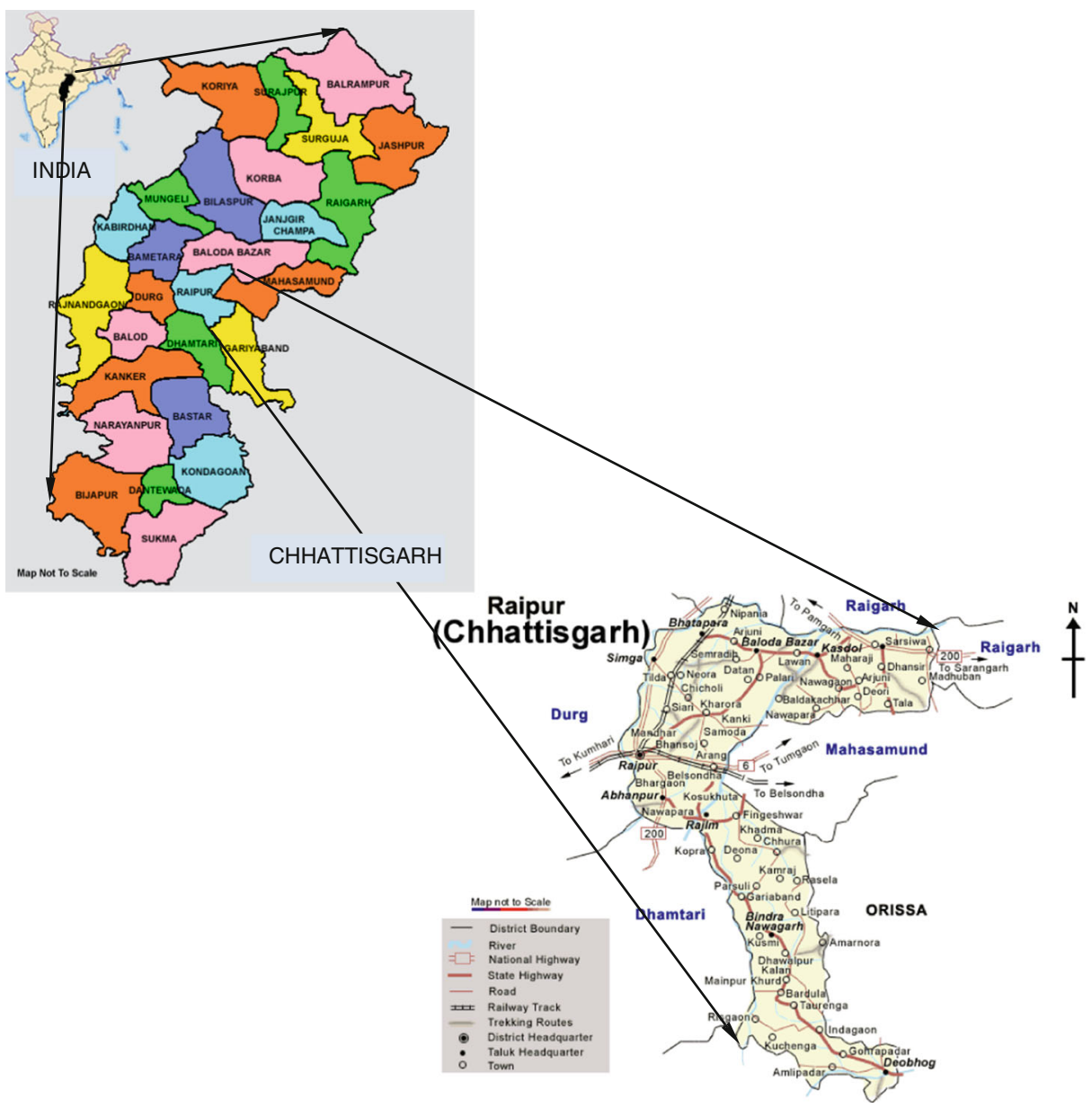

Fig. 1 Location map of Raipur in Chhattisgarh state of India

\subsection{Tests for Change Point Detection}

The change point detection is an important aspect to assess the period from where significant change has occurred in a time series. Pettitt's test, von Neumann ratio test, Buishand range test and standard normal homogeneity tests have been applied for change point detection in climatic series. The details of various change point tests applied in the study are presented here.

\subsubsection{Pettitt's Test}

A number of methods can be applied to determine change points of a time series by many researchers such as Hawkins (1977), Buishand (1982), Kim and Siegmund (1989), Chen and Gupta (2001), Radziejewski et al. (2000), Lund et al. (2002), Rodionov (2004), Seidel and Lanzante (2004), Menne et al. (2005), Bryson et al. (2012), Gallagher et al. (2012), Li and 
Table 1 Statistical information of different meteorological variables at Raipur (Chhattisgarh)

\begin{tabular}{|c|c|c|c|c|c|c|c|c|c|c|c|c|}
\hline \multirow{2}{*}{$\begin{array}{l}\text { Month/ } \\
\text { Season }\end{array}$} & \multicolumn{4}{|c|}{ Minimum temperature $\left({ }^{\circ} \mathrm{C}\right)$} & \multicolumn{4}{|c|}{ Maximum temperature $\left({ }^{\mathrm{o}} \mathrm{C}\right)$} & \multicolumn{4}{|c|}{ Relative humidity (\%) } \\
\hline & Min & Max & Mean & St. Dv & Min & Max & Mean & St. Dv & Min & Max & Mean & St. Dv \\
\hline January & 8.4 & 14.3 & 11.3 & 1.6 & 24.1 & 30.3 & 27.5 & 1.3 & 47.9 & 75.9 & 61.6 & 6.9 \\
\hline February & 10.5 & 15.7 & 13.9 & 1.4 & 27.6 & 33.5 & 30.4 & 1.4 & 39.4 & 71.0 & 55.9 & 7.8 \\
\hline March & 15.5 & 20.7 & 17.8 & 1.2 & 32.5 & 37.7 & 35.3 & 1.4 & 30.5 & 61.0 & 44.2 & 7.5 \\
\hline April & 20.3 & 25.1 & 22.6 & 1.0 & 36.6 & 42.6 & 39.8 & 1.3 & 22.9 & 45.5 & 34.0 & 5.5 \\
\hline May & 23.6 & 28.0 & 26.3 & 1.2 & 37.0 & 44.2 & 42.0 & 1.5 & 22.3 & 56.6 & 33.0 & 8.4 \\
\hline June & 23.7 & 28.6 & 26.1 & 1.2 & 32.8 & 41.3 & 37.4 & 2.1 & 42.1 & 75.4 & 57.7 & 9.2 \\
\hline July & 22.3 & 25.8 & 24.2 & 0.8 & 29.0 & 34.3 & 31.2 & 1.1 & 68.4 & 86.6 & 80.3 & 4.2 \\
\hline August & 21.8 & 25.6 & 24.1 & 0.8 & 28.7 & 31.2 & 30.0 & 0.7 & 78.9 & 87.5 & 84.1 & 2.3 \\
\hline September & 22.4 & 25.8 & 24.0 & 0.7 & 29.2 & 32.8 & 31.0 & 0.8 & 75.4 & 86.9 & 81.1 & 3.2 \\
\hline October & 18.3 & 24.8 & 20.8 & 1.2 & 29.2 & 33.7 & 31.1 & 0.9 & 65.6 & 80.3 & 73.3 & 4.0 \\
\hline November & 11.8 & 20.5 & 15.1 & 2.1 & 27.4 & 31.9 & 29.4 & 1.1 & 56.4 & 76.1 & 65.0 & 4.8 \\
\hline December & 8.2 & 15.7 & 11.2 & 1.7 & 25.3 & 29.7 & 27.5 & 1.1 & 49.3 & 81.2 & 61.9 & 6.2 \\
\hline Annual & 18.3 & 21.5 & 19.8 & 0.7 & 31.7 & 33.9 & 32.7 & 0.4 & 56.1 & 67.5 & 61.0 & 2.6 \\
\hline Summer & 21.5 & 25.4 & 23.2 & 0.9 & 36.0 & 40.4 & 38.6 & 0.9 & 32.5 & 51.6 & 41.8 & 4.7 \\
\hline Rainy & 21.9 & 25.4 & 23.3 & 0.7 & 29.6 & 32.0 & 30.8 & 0.6 & 69.7 & 81.6 & 75.3 & 2.9 \\
\hline Winter & 10.7 & 14.7 & 12.8 & 1.0 & 27.4 & 30.2 & 28.7 & 0.7 & 53.9 & 70.2 & 61.1 & 4.1 \\
\hline \multirow{2}{*}{$\begin{array}{l}\text { Month/ } \\
\text { Season }\end{array}$} & \multicolumn{4}{|c|}{ Wind speed $(\mathrm{km} / \mathrm{h})$} & \multicolumn{4}{|c|}{ Sunshine hour (hr) } & \multicolumn{4}{|c|}{ Pan evaporation (mm) } \\
\hline & Min & Max & Mean & St. Dv & Min & Max & Mean & St. Dv & Min & Max & Mean & St. Dv \\
\hline January & 0.8 & 4.3 & 2.9 & 0.9 & 4.9 & 9.5 & 8.0 & 1.1 & 2.4 & 3.7 & 3.1 & 0.4 \\
\hline February & 1.8 & 5.8 & 3.8 & 1.0 & 6.9 & 10.4 & 8.8 & 0.8 & 3.0 & 4.8 & 3.7 & 0.4 \\
\hline March & 2.5 & 6.9 & 4.8 & 1.1 & 7.1 & 10.0 & 9.0 & 0.6 & 5.2 & 8.7 & 6.7 & 0.8 \\
\hline April & 4.1 & 9.8 & 6.7 & 1.4 & 8.0 & 10.4 & 9.2 & 0.7 & 7.9 & 12.1 & 10.1 & 1.1 \\
\hline May & 4.5 & 11.2 & 8.3 & 1.5 & 6.3 & 11.5 & 8.5 & 1.2 & 7.8 & 17.8 & 12.4 & 1.9 \\
\hline June & 8.0 & 14.7 & 11.2 & 1.6 & 2.4 & 7.3 & 4.7 & 1.3 & 4.9 & 11.7 & 9.0 & 1.8 \\
\hline July & 6.3 & 14.4 & 10.5 & 2.0 & 1.2 & 4.4 & 2.9 & 0.8 & 2.8 & 7.0 & 4.3 & 0.9 \\
\hline August & 3.5 & 13.6 & 9.1 & 2.4 & 0.7 & 6.0 & 3.1 & 1.0 & 2.7 & 4.3 & 3.5 & 0.4 \\
\hline September & 1.4 & 9.4 & 5.8 & 1.7 & 2.9 & 7.3 & 5.5 & 1.1 & 2.9 & 4.5 & 3.8 & 0.4 \\
\hline October & 1.5 & 5.2 & 3.3 & 0.8 & 6.1 & 9.7 & 8.1 & 0.9 & 3.0 & 4.2 & 3.7 & 0.3 \\
\hline November & 0.9 & 4.4 & 2.9 & 0.9 & 6.3 & 9.8 & 8.2 & 1.1 & 2.7 & 4.1 & 3.2 & 0.3 \\
\hline December & 0.7 & 8.0 & 2.6 & 1.1 & 3.6 & 9.7 & 8.0 & 1.0 & 2.3 & 3.7 & 2.8 & 0.3 \\
\hline Annual & 3.7 & 7.8 & 6.0 & 1.1 & 6.2 & 7.6 & 7.0 & 0.4 & 4.8 & 6.2 & 5.5 & 0.3 \\
\hline Summer & 5.3 & 9.8 & 7.8 & 1.1 & 6.5 & 9.0 & 7.9 & 0.6 & 7.7 & 11.2 & 9.6 & 0.9 \\
\hline Rainy & 4.1 & 9.6 & 7.2 & 1.5 & 3.5 & 5.9 & 4.9 & 0.6 & 3.2 & 4.6 & 3.8 & 0.3 \\
\hline Winter & 1.4 & 5.0 & 3.1 & 0.8 & 7.1 & 9.2 & 8.3 & 0.5 & 2.8 & 3.7 & 3.2 & 0.2 \\
\hline
\end{tabular}

Lund (2012), and many more. The Pettitt's test for change detection, developed by Pettitt (1979), is a non-parametric test, which is useful for evaluating the occurrence of abrupt changes in climatic records (Smadi and Zghoul 2006; Sneyers 1990; Tarhule and Woo 1998; Verstraeten et al. 2006; Mu et al. 2007; Zhang and Lu 2009; Gao et al. 2011). The Pettitt's test is the most commonly used test for change point detection because of its sensitivity to breaks in the middle of any time series (Winingaard et al. 2003). Kang and Yusof (2012), Dhorde and Zarenistanak (2013) and many others have explained the test statistics used in Pettitt's test.

The Pettitt's test is a method that detects a significant change in the mean of a time series when the exact time of the change is unknown. According to Pettitt's test, if $x_{1}, x_{2}, x_{3}, \ldots x_{n}$ is a series of observed data which has a change point at $t$ in such a way that $x_{1}, x_{2} \ldots, x_{t}$ has a 
distribution function $F_{1}(x)$ which is different from the distribution function $F_{2}(x)$ of the second part of the series $x_{t+1}, x_{t+2}, x_{t+3} \ldots, x_{n}$. The non-parametric test statistics $U_{t}$ for this test may be described as follows:

$$
\begin{gathered}
U_{t}=\sum_{i=1}^{t} \sum_{j=t+1}^{n} \operatorname{sign}\left(x_{t}-x_{j}\right) \\
\operatorname{sign}\left(x_{t}-x_{j}\right)=\left[\begin{array}{cc}
1, & \text { if }\left(x_{i}-x_{j}\right)>0 \\
0, & \text { if }\left(x_{i}-x_{j}\right)=0 \\
-1, & \text { if }\left(x_{i}-x_{j}\right)<0
\end{array}\right]
\end{gathered}
$$

The test statistic $K$ and the associated confidence level $(\rho)$ for the sample length $(n)$ may be described as:

$$
\begin{gathered}
K=\operatorname{Max}\left|U_{t}\right| \\
\rho=\exp \left(\frac{-\mathrm{K}}{\mathrm{n}^{2}+\mathrm{n}^{3}}\right)
\end{gathered}
$$

When $\rho$ is smaller than the specific confidence level, the null hypothesis is rejected. The approximate significance probability $(p)$ for a change-point is defined as given below:

$$
p=1-\rho
$$

It is obvious that where a significant change point exists, the series is segmented at the location of the change point into two subseries. The test statistic $K$ can also be compared with

\begin{tabular}{|c|c|c|c|c|c|c|c|c|}
\hline \multirow[t]{3}{*}{ Number of observation } & \multicolumn{8}{|c|}{ Critical values for test statistic at different significance level } \\
\hline & \multicolumn{2}{|c|}{ Pettit Test } & \multicolumn{2}{|c|}{ SNHT } & \multicolumn{2}{|c|}{ Buishand Range test $(R / \sqrt{ } n)$} & \multicolumn{2}{|c|}{ von Neumann Ratio test } \\
\hline & $1 \%$ & $5 \%$ & $1 \%$ & $5 \%$ & $1 \%$ & $5 \%$ & $1 \%$ & $5 \%$ \\
\hline 20 & 71 & 57 & 9.56 & 6.95 & 1.60 & 1.43 & 1.04 & 1.30 \\
\hline 30 & 133 & 107 & 10.45 & 7.65 & 1.70 & 1.50 & 1.20 & 1.42 \\
\hline 40 & 208 & 167 & 11.01 & 8.10 & 1.74 & 1.53 & 1.29 & 1.49 \\
\hline 50 & 293 & 235 & 11.38 & 8.45 & 1.78 & 1.55 & 1.36 & 1.54 \\
\hline 70 & 488 & 393 & 11.89 & 8.80 & 1.81 & 1.59 & 1.45 & 1.61 \\
\hline 100 & 841 & 677 & 12.32 & 9.15 & 1.86 & 1.62 & 1.54 & 1.67 \\
\hline
\end{tabular}
standard values at different confidence level for detection of change point in a series. The critical values of $K$ at 1 and $5 \%$ confidence levels for different tests used in the analysis has been presented in Table 2 (Winingaard et al. 2003).

Table 2 Critical values of test statistics for different change point detection tests 


\subsection{2 von Neumann Ratio Test}

The von Neumann ratio test is closely related to first-order serial correlation coefficient (WMO 1966). The test has been described by Buishand (1982), Kang and Yusof (2012) and others. The test statistics for change point detection in a series of observations $x_{1}, x_{2}, x_{3} \ldots x_{n}$ can be described as:

$$
N=\frac{\sum_{i=1}^{n-1}\left(x_{i}-x_{i-1}\right)^{2}}{\sum_{i=1}^{n}\left(x_{i}-\bar{x}\right)^{2}}
$$

According to this test, if the sample or series is homogeneous, then the expected value $E(N)=2$ under the null hypothesis with constant mean. When the sample has a break, then the value of $N$ must be lower than 2, otherwise we can imply that the sample has rapid variation in the mean. Owen (1962) has produced a table showing percentage points on $N$ for normally distributed samples. The critical values of $N$ at 1 and $5 \%$ confidence levels given in Table 2 can be used for identification of non-homogeneous series with change point.

\subsubsection{Buishand's Range Test (Buishand 1982)}

The adjusted partial sum $\left(S_{k}\right)$, that is the cumulative deviation from mean for $k^{\text {th }}$ observation of a series $x_{1}, x_{2}, x_{3} \ldots x_{k} \ldots x_{n}$ with mean $(\bar{x})$ can be computed using following equation:

$$
S_{k}=\sum_{i=1}^{k}\left(x_{i}-\bar{x}\right)
$$

A series may be homogeneous without any change point if $S_{k \cong} 0$, because in random series, the deviation from mean will be distributed on both sides of the mean of the series. The significance of shift can be evaluated by computing rescales adjusted range $(R)$ using the following equation:

$$
R=\frac{\operatorname{Max}\left(S_{k}\right)-\operatorname{Min}\left(S_{k}\right)}{\bar{x}}
$$

The computed value of $R / \sqrt{n}$ is compared with critical values given by Buishand (1982) and Winingaard et al. (2003) and has been used for detection of possible change (Table 2).

\subsubsection{Standard Normal Homogeneity (SNH) Test (Alexandersson 1986)}

The test statistic $\left(T_{k}\right)$ is used to compare the mean of first $n$ observations with the mean of the remaining ( $n-k)$ observations with $n$ data points (Stepanek et al. 2009; Vezzoli at al. 2012).

$$
T_{k}=k Z_{1}^{2}+(n-k) Z_{2}^{2}
$$


$Z_{1}$ and $Z_{2}$ can be computed as:

$$
\begin{gathered}
Z_{1}=\frac{1}{k} \sum_{i=1}^{k} \frac{\left(x_{i}-\bar{x}\right)}{\sigma x} \\
Z_{2}=\frac{1}{n-k} \sum_{i=k+1}^{n} \frac{\left(x_{i}-\bar{x}\right)}{\sigma x}
\end{gathered}
$$

where, $\bar{x}$ and $\sigma x$ are the mean and standard deviation of the series. The year $k$ can be considered as change point and consist a break where the value of $T_{k}$ attains the maximum value. To reject the null hypothesis, the test statistic should be greater than the critical value, which depends on the sample size $(n)$ given in Table 2.

\subsection{Tests for Trend Analysis}

The trends in historical series of meteorological data have been assessed using linear regression test, Mann-Kendall and Spearman's rho tests, as described here.

\subsubsection{Linear Regression Test}

In linear regression test, a straight line is fitted to the data and the slope of the line may be significantly different from zero or not. For a series of observations $x_{i}, i=1,2,3, \ldots n$, a straight line in the form of $y=a+b x$ is fitted to the data and then the test statistics $(t)$ can be computed as:

$$
\begin{gathered}
a=\bar{y}-b \bar{x} \\
b=\frac{\sum\left(x_{i}-\bar{x}\right)\left(y_{i}-\bar{y}\right)}{\sum\left(x_{i}-\bar{x}\right)^{2}} \\
\sum \varepsilon^{2}=\sum(y-\bar{y})^{2}-b \sum(x-\bar{x})^{2} \\
S_{b}=\frac{\varepsilon_{i}^{2}}{(n-2) \sum(x-\bar{x})^{2}} \\
t=\frac{b}{S_{b}}
\end{gathered}
$$


where, $\mathrm{a}, \mathrm{b}$ are the intercept and slope of fitted line, respectively, $\sum \varepsilon^{2}$ is the sum of squares of residuals or errors and $S_{b}$ is the standard error of $b$. The hypothesis in this test is confirmed using students $t$-test.

\subsubsection{Mann-Kendall Test}

Mann-Kendall test is a non-parametric test which does not require the data to be normally distributed; this test has low sensitivity to abrupt breaks due to inhomogeneous time series (Tabari et al. 2011). This test has been recommended widely by the World Meteorological Organization for public application (Mitchell et al. 1996). Furthermore, Hirsch et al. (1982), Burn and Elnur (2002), Yue et al. (2003), Yue and Pilon (2004), Kahya and Kalayci (2004), Yue and Wang (2004), Gadgil and Dhorde (2005), Modarres and Da silva (2007), Marvomatis and Stathis (2011), Tabari and Marofi (2011) and many more have used this test for evaluating the trend in climatic, hydrological and water resources data. In this test, each value in the series is compared with others, always in sequential order. The Mann-Kendall statistic can be written as:

$$
S=\sum_{i=1}^{n} \sum_{j=1}^{i-1} \operatorname{sign}\left(x_{i}-x_{j}\right)
$$

where, $n$ is the total length of data, $x_{i}$ and $x_{j}$ are two generic sequential data values, and function $\operatorname{sign}\left(x_{i}-x_{j}\right)$ assumes the following values

$$
\operatorname{sign}\left(x_{i}-x_{j}\right)=\left[\begin{array}{cl}
1, & \text { if }\left(x_{i}-x_{j}\right)>0 \\
0, & \text { if }\left(x_{i}-x_{j}\right)=0 \\
-1, & \text { if }\left(x_{i}-x_{j}\right)<0
\end{array}\right]
$$

Under this test, the statistic $S$ is approximately normally distributed with the mean $E(S)$ and the variance $\operatorname{Var}(S)$ can be computed as follow:

$$
\begin{gathered}
E(S)=0 \\
\operatorname{Var}(S)=\frac{1}{n}\left[n(n-1)(2 n+5)-\sum_{t} t(t-1)(2 t+5)\right]
\end{gathered}
$$

where, $n$ is the length of time series, and $t$ is the extent of any given tie and $\Sigma t$ denotes the summation over all tie number of values. The standardized statistics $Z$ for this test can be computed by the following equation:

$$
Z=\left[\begin{array}{lr}
\frac{S+1}{\sqrt{\operatorname{Var}(S)}}, & \text { if } S>0 \\
0, & \text { if } S=0 \\
-1, & \text { if } S<0
\end{array}\right]
$$

In this test, the null hypothesis $H_{0}$ is confirmed if a data set of $n$ independent randomly distributed variables has no trend with equally likely ordering. Any positive value of test statistic $Z$ indicates a rising, while a negative value may conclude a declining trend in series. The computed absolute value of $Z$ is compared with the standard normal cumulative value of 
$Z(1-p / 2)$ at $p \%$ significance level obtained from standard table to accept or reject null hypothesis and ascertain the significance of trend (Partal and Kahya 2006).

\subsubsection{Spearman's Rho Test}

The Spearman's rho test is a non-parametric method proposed and applied in the literature for trend analysis (Environmental Protection 1973; Lettenmaier 1976; Sweitzer and Kolaz 1984; Sadmani et al. 2012 etc.). This is one of the important non-parametric tests widely used for studying populations that take on a ranked order. If there is no trend and all observations are independent, then all rank orderings are equally likely. In this test, the difference between order and rank $\left(d_{i}\right)$ for all observations $x_{1}, x_{2}, x_{3}, \ldots \ldots x_{n}$ can be used to compute and Spearman's $\rho$, variance $\operatorname{Var}(\rho)$ and test statistic $(\mathrm{Z})$ using following equations.

$$
\begin{aligned}
& \rho=1-\frac{6 \sum d_{i}^{2}}{n(n-1)} \\
& \operatorname{Var}(\rho)=\frac{1}{(n-1)} \\
& Z=\frac{\rho}{\sqrt{\operatorname{Var}(\rho)}}
\end{aligned}
$$

The null hypothesis is tested in this test considering the statistic is normally distributed.

\section{Analysis of Results}

In the present study, first various change point tests including Pettitt's test, von Neumann's ratio test, Buishand's range test and SNH test have been applied to detect change point in monthly, annual and seasonal series of different climatic parameters of Raipur. After detecting a change point, trend analysis was applied using linear regression test, Mann-Kendall test and Spearman's rho test in the time series. The results of change point and trend analysis are described here.

\subsection{Results of Change Point Analysis}

For carrying out change detection analysis, mean monthly, annual and seasonal (summer, rainy and winter) series of minimum temperature, maximum temperature, relative humidity, wind speed, sunshine hour and pan evaporation have been analyzed with the help of Pettitt's test, SNH test, Buishand range test and von Neumann ratio test. The test statistic of various tests and acceptance or rejection of null hypothesis for minimum temperature has been presented in Table 3. For selecting the change point for a particular parameter, the method presented below has been used (Winingaard et al. 2003): 


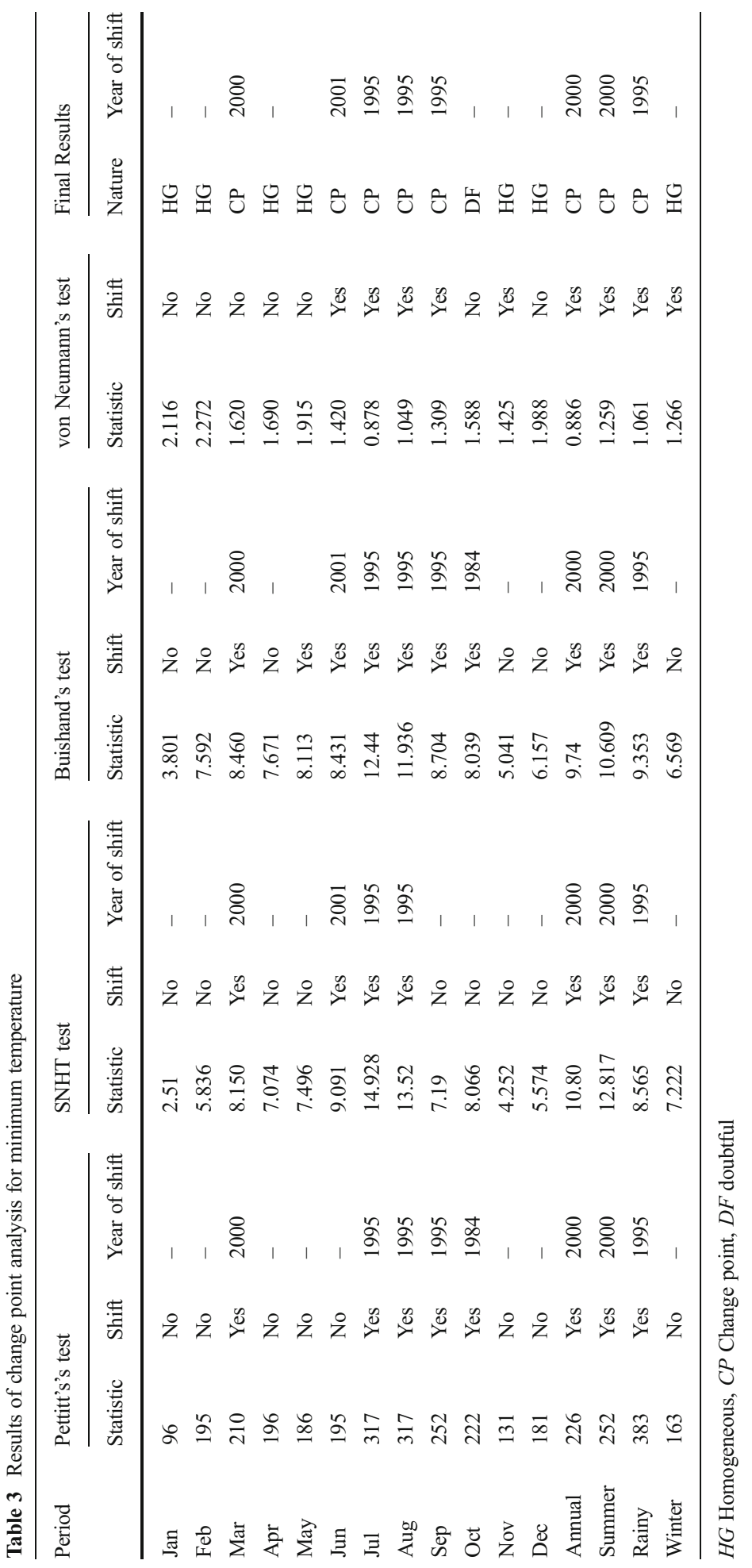




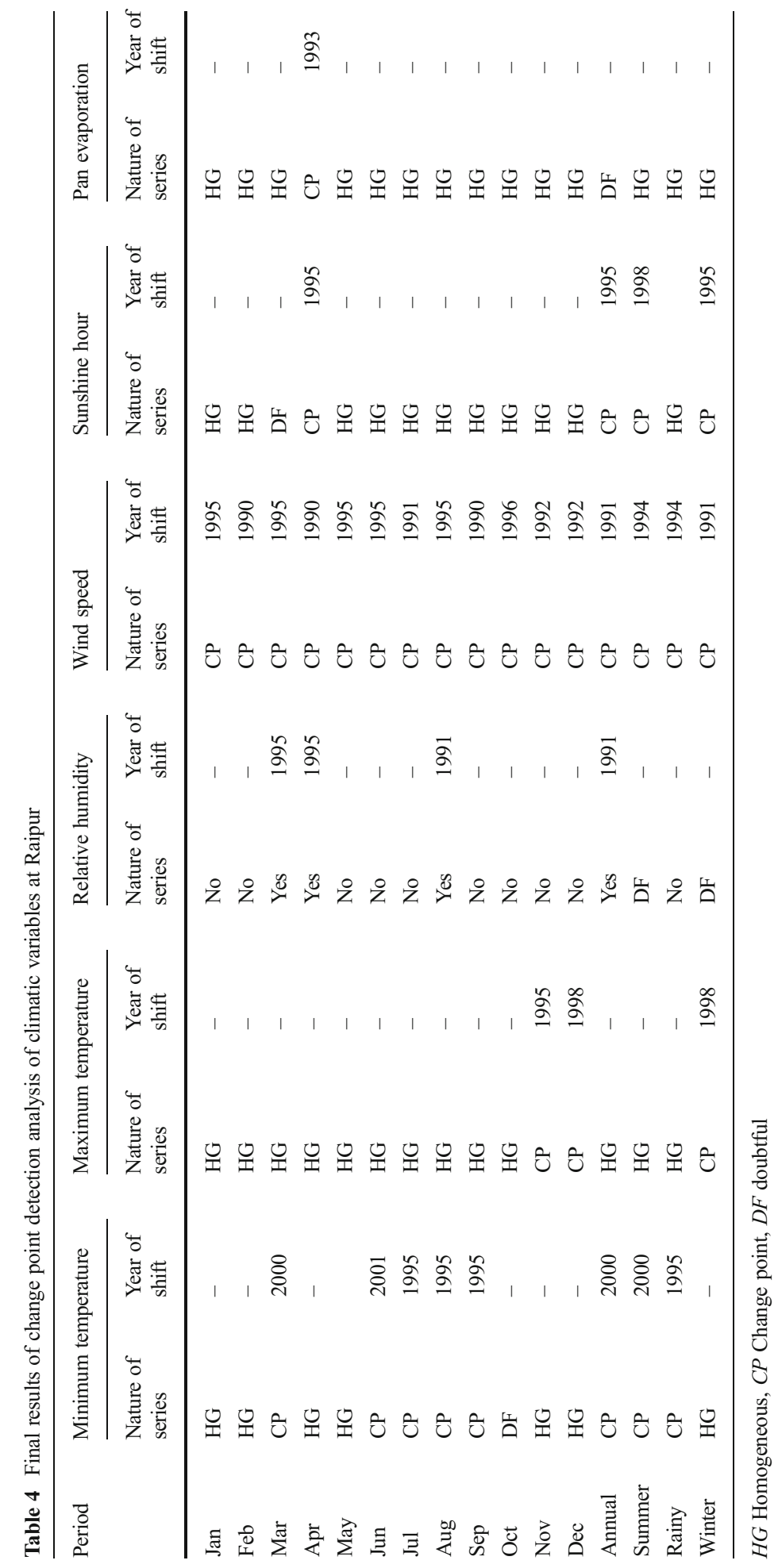



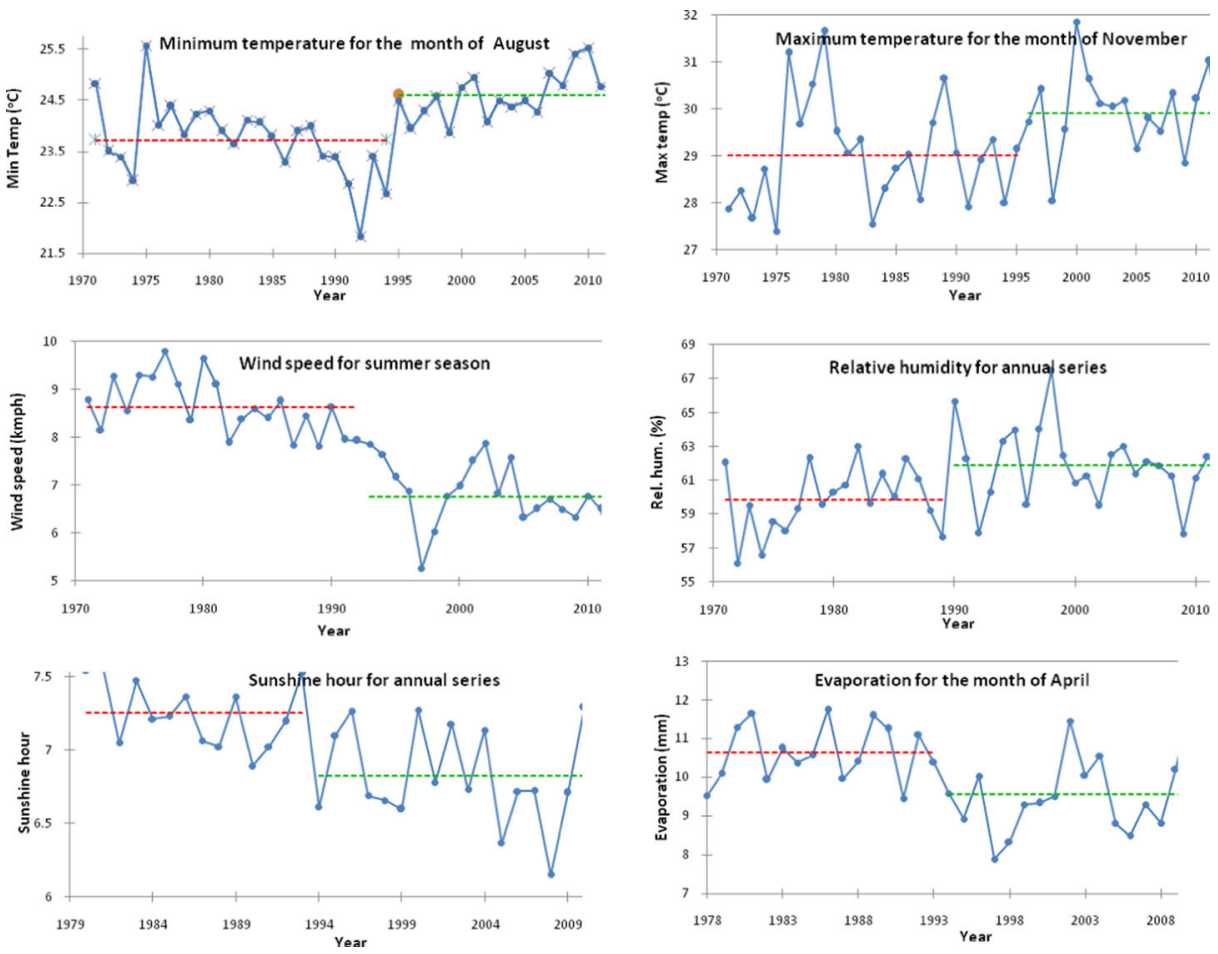

Fig. 2 Change points in historical series of meteorological variables at Raipur

a) No change point or homogeneous (HG): A series may be considered as homogeneous, if no or one test out of four tests rejects the null hypothesis at $5 \%$ significant level.

b) Doubtful series (DF): A series may be considered as inhomogeneous and critically evaluated before further analysis if two out of four tests reject the null hypothesis at $5 \%$ significant level.

c) Change point or inhomogeneous (CP): A series may has change point or be inhomogeneous in nature, if more than two tests reject the null hypothesis at $5 \%$ significant level.

The final results depicting the homogeneity state of different series have been presented in Table 4. The graphical representation of historical series of few climatic variables with the change points have been presented in Fig. 2. The minimum temperature series of March, July, August, September, annual, summer and rainy season indicated a significant change point, while other series can be considered as homogeneous in nature. The change point analysis on long-term series of maximum temperature has indicated that a significant change point in the series of November and December exists which produced a change point in winter series also. The change point analysis of relative humidity confirmed that the change point may occur in 1995 in March and April series, while the same has found in the year 1991 for August and annual series. All monthly, seasonal and annual series of wind speed present significant change points in 1990 to 1996 at $95 \%$ confidence level. The sunshine hour data indicated change point in April, annual, summer and winter season with 1995 as change point in most of the cases. The behavior of historical series of pan evaporation confirmed that April series has significant change point while annual series 


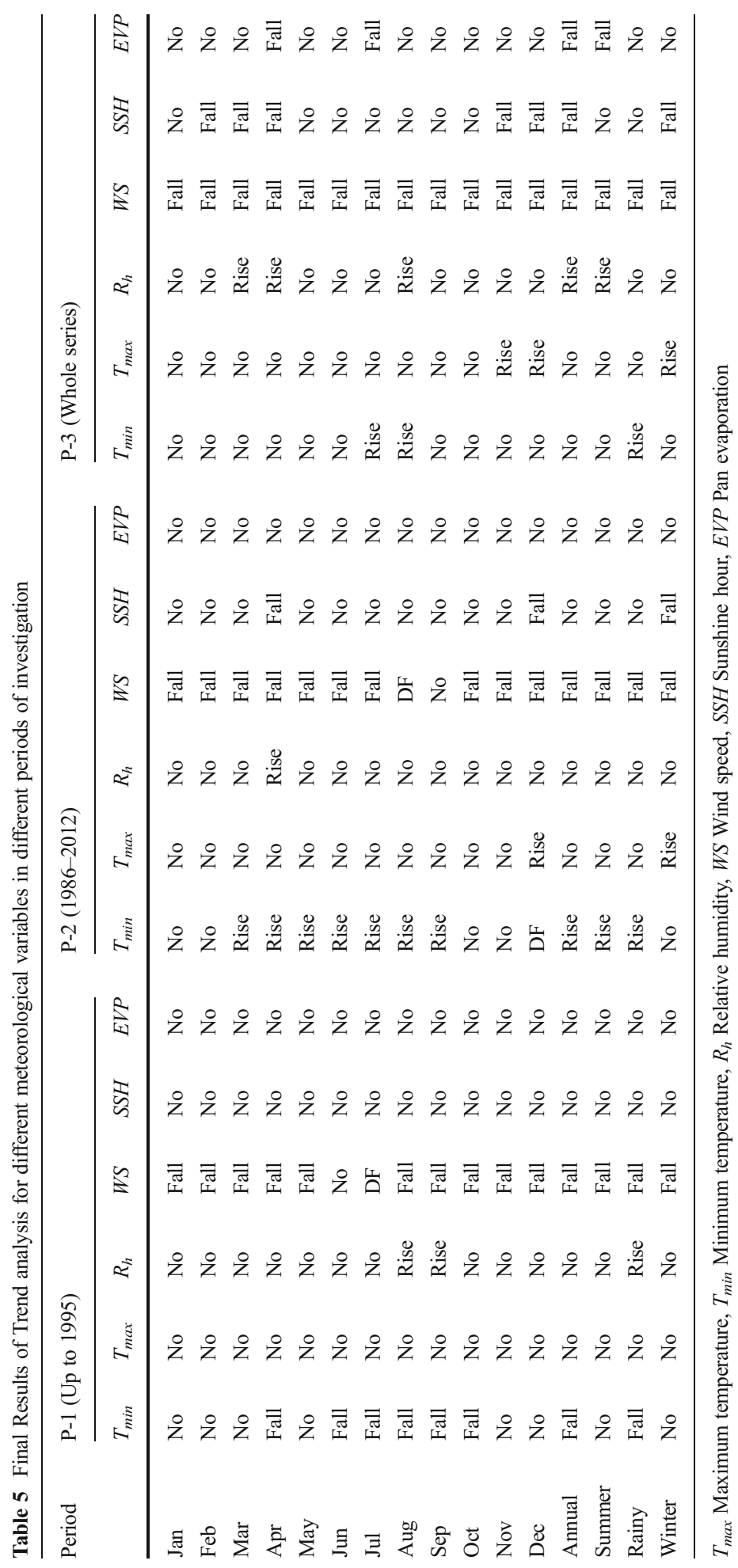


should be investigated further using more tests while all other series are homogeneous in nature.

\subsection{Trend Detection Analysis}

The results of change point analysis indicated that most of the series are homogeneous; however, some of the variables indicated a change point between 1990 and 2000 which may be due to increased industrial and commercial activities in the region as this city was nominated as the capital of proposed Chhatisgarh state. Therefore, considering the results of change point analysis and by dividing the series in nearly equal length, the trend analysis of different climatic variables has been carried out for three different periods namely P-1 (covers time series up to 1995), P-2 (covers time series from 1986 to 2012) and P-3 covers the whole series of a variable. For determination of trend, linear regression test, the Mann-Kendall test and the Spearman's rho test have been applied in the different series of meteorological variables. The methodology suggested by Winingaard et al. (2003) has been used to arrive at decision of trend in the series of different meteorological variables. The final results of trends in meteorological variables in different time horizons have been presented in Table 5. The results of the trend analysis of different meteorological variables are presented below.

The minimum temperature in the first period up to 1995 (P-1) showed a significant falling trend in April, June, July, August, September, October, annual and rainy seasons series at $5 \%$ significance level. The trend pattern indicated a significant rise in minimum temperature during March to September, annual, summer and rainy season series during period 1986 to 2012 (P-2) and also a rise in July, August and rainy season in whole series from 1971 to 2012
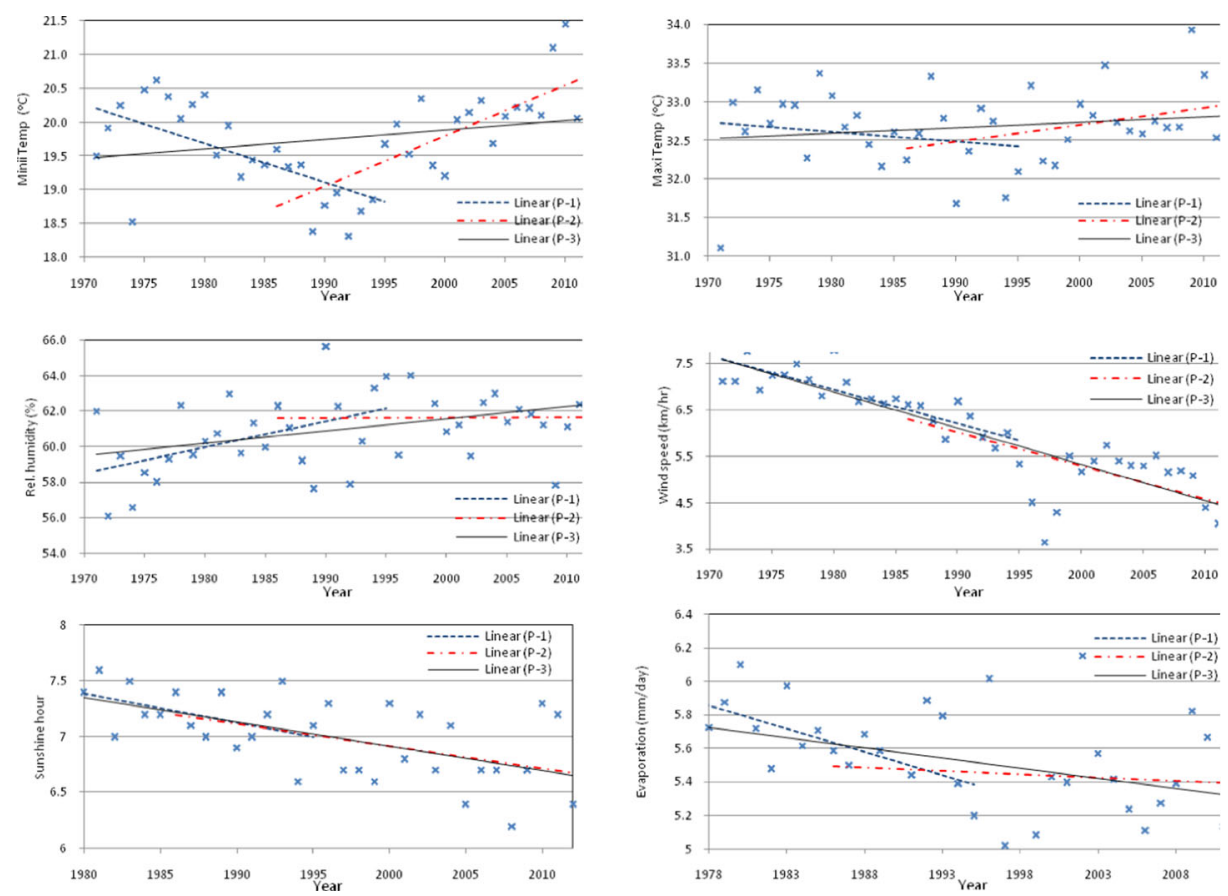

Fig. 3 Trends in annual series of meteorological variables during different time periods 
(P-3). From the analysis of results of trends, it may be concluded that the minimum temperature series show a rising trend in the months of the rainy season. The analysis of maximum temperature series at Raipur shows a rising trend in December series in P-2 period and in November, December and winter season in the whole series (P-3). No series in P-1 (up to 1995) period indicated any trend and it may be concluded that the maximum temperature were randomly distributed prior to 1995 . A change may occur after the $1980 \mathrm{~s}$ in the form of rising trend due to possible human intervention and/or climate change. The relative humidity pattern at Raipur indicated a rising trend in August, September and rainy season of period P-1. In second period P-2, a significant rising trend has been observed in April, while the whole series (P-3) exhibited a significant rising trend in the series of March, April, August, annual and summer season. It may be concluded that the relative humidity in the region shows a positive trend in annual and summer months.

The trend analysis of wind speed series at Raipur for all three periods P-1, P-2 and P-3 indicated a significant falling trend in almost all monthly, annual and seasonal series. The trends of sunshine hours obtained from different trend analysis tests indicated that all the series were randomly distributed during period P-1. In second period P-2, the sunshine hour series indicated a significant falling trend during April, December and winter season. When the whole series (P-3) of sunshine hour was tested for detection of statistical trends, a significant falling trend has been observed in February, March, April, November, December, annual and winter season. From the analysis of results, it may be concluded that there may be a systematic falling trend in sunshine hour at Raipur after the seventies. The results of trend tests on pan evaporation indicated that all monthly, annual and seasonal series are randomly distributed during periods P-1 and P-2. In case of P-3, a significantly falling trend may be observed in April, July, annual and summer series of pan evaporation data. The annual trends in different time periods of all climatic variables have been depicted in Fig. 3 that indicated positive trend in annual minimum temperature, maximum temperature and relative humidity while negative trend in annual wind speed, sunshine hour and evaporation series mostly in all three periods when data fitted linearly.

\section{Conclusions}

The assessment of temporal variability in different climatic variables due to possible climate change or human intervention is important for water resources planning and management at the regional and local scale. In the present study, change point detection followed by trend analysis has been carried out using different non-parametric statistical tests. The change point has been detected using Pettitt's test, von Neumann ratio test, Buishand's range test and standard normal homogeneity test on monthly, seasonal and annual long-term series of minimum temperature, maximum temperature, relative humidity, wind speed, sunshine hour and pan evaporation of Raipur, a capital city of Chhattisgarh state of India. The change point analysis results of minimum temperature, relative humidity, sunshine hour and evaporation confirmed a significant change point in few summer months and summer seasonal series. The maximum temperature had breaks in few winter months and winter seasonal series, while all monthly, seasonal and annual series of wind speed indicated significant change point. The significant change points in these series observed during 1900 to 2000 may attribute the influence of fast growing industrial and commercial activities in the region. 
The trend analysis of minimum and maximum temperature indicated a significant falling or no trend prior to 1995 (P-1) which turned to a rising trend in period 1986 to 2012 (P-2) and complete series from 1971 to 2012 (P-3) series of rainy months, annual, summer and rainy season in case of minimum temperature and winter months and winter season series of maximum temperature. The increasing trend in temperature series may indicate possible combined impact of climate change and fast development in the study area. The significant rising trends have been observed in few summer and rainy months and annual series of relative humidity in all three periods. Most of the monthly, seasonal and annual series of wind speed in all three periods confirmed a significant falling trend using statistical analysis. The sunshine hour and pan evaporation series were distributed randomly prior to year 1995, and indicated falling trend in few summer and winter monthly and seasonal series of sunshine hour and April, July, summer and annual series of pan evaporation. The statistical trend analysis of meteorological variables concludes that the minimum and maximum temperature confirmed a significant rising trend in summer and winter months, respectively, that may impact crop production and water availability in the region. The possible impact of this rising trend may not be visible on pan evaporation and may be due to strong falling trend of wind speed and falling trend of sunshine hour series. It may be concluded from the analysis that most of the series that indicate change point also confirmed a significant trend in P-2 and/or P-3 periods.

\section{References}

Al Buhairi MH (2010) Analysis of monthly, seasonal and annual air temperature ariability and trends in Taiz city - Republic of Yemen. J Environ Protect 1:401-409

Alexandersson HA (1986) A homogeneity test applied to precipitation data. Int J Climatol 6:661-675

Aderson TW (1994) The statistical analysis of time series. John Willy \& Sons

Baseville M, Nikiforov IV (1993) Detection of abrupt change: theory and application. Prentice and Hall, Upper Saddle River, NJ

Bates BC, Chandler RE, Charles SP, Campbell EP (2010) Assessment of apparent non-stationarity in time series of annual inflow, daily precipitation and atmospheric circulation indices: A case study from southwest Australia. Water Resour Res 46:W00H02. doi:10.1029/2010WR009509

Bavani AM, Goodarji E, Johrabi N (2012) Detection of climatic variables trend by using parametric and non parametric statistical tests (A case study of West Azerbaijan, Iran). Technol J Eng App Sci 2(S):557-564

Boroujerdy PS (2008) The analysis of precipitation variation and quantiles in Iran 3rd IASME/WSEAS. Int Conf on Energy and Environ, University of Cambridge UK

Bryson CB, Richard EC, Adrian WB (2012) Trend estimation and change point detection in individual climatic series using flexible regression methods. J Geophys Res 117:D16106. doi:10.1029/2011JD017077

Buishand TA (1982) Some methods for testing the homogeneity of rainfall records. J Hydrol 58(1-2):11-27

Burn DH, Elnur MA (2002) Detection of hydrologic trends and variability. J Hydrol 255(1-4):107-122

Chen J, Gupta A (2001) On change point detection and estimation, Communications in Statistics. Simul Comput 30(3):665-697

Croitoru A, HolobacaI H, Catalin LC, Moldovan F, Imbroane A (2012) Air temperature trend and the impact on winter wheat phenology in Romania. Climate Change 111(2):393-41

Dhorde AG, Zarenistanak M (2013) Three-way approach to test data homogeneity: an analysis of temperature and precipitation series over southwestern Islamic Republic of Iran. J Ind Geophys Union 17(3):233-242

Elsner JB, Niu X, Jagger TH (2004) Detecting shifts in hurricane rates using a Markov chain Monte Carlo approach. J Clim 17:2652-2666. doi:10.1175/1520-0442(2004)017<2652:DSIHRU>2.0.CO;2

Environmental Protection Agency (1973) The national air monitoring program: air quality and emissions trends annual report. US Environmental Protection Agency, Office of Air Quality Planning and Standards, Research Triangle Park, North Carolina (450/1-73-001a and b)

Eslamian S, Hassanzadeh H, Khordadi MH (2009) Detecting and evaluting climate change effect on frequency analysis of wind speed. Int J Global Energy. doi:10.1504/IJGEL.2009.030657

Fealy R, Sweeney J (2005) Detection of a possible change point in atmospheric variability in the north Atlantic and its effect on Scandinavian glacier mass balance. Int J Climatol 25:1819-1833. doi:10.1002/joc.1231 
Food and Agricultural Organization (2001) Global Forest Resources Assessment 2000: Main Report Forestry Paper 140, Rome

Fu GB, Charles SP, Viney NR, Chen S, Wu JQ (2007) Impacts of climate variability on stream-flow in the Yellow River. Hydrol Process 21(25):3431-3439

Gadgil A, Dhorde A (2005) Temperature trends in twentieth century at Pune, India. Atmos Environ 39:65506556

Gallagher C, Lund R, Robbins M (2012) Change point detection in climate time series with long-term trends. J Clim 26:4994-5006. doi:10.1175/JCLI-D-12-00704.1

Gao P, Mu XM, Li R, Wang W (2009) Trend and driving force analyses of streamflow and sediment discharge in Wuding River. J Sediment Res 5:22-28

Gao P, Mu XM, Wang F, Li R (2011) Changes in streamflow and sediment discharge and the response to human activities in the middle reaches of the Yellow River. Hydrol Earth Syst Sci 15:1-10

Ghahraman B, Taghvaeian S (2008) Investigation of annual rainfall trends in Iran. J Agric Sci Technol 10:93-97

Gonzalez-Rouco JF, Jimenez JL, Quesada V, Valero F (2001) Quality control and homogeneity of precipitation data in the southwest of Europe. Int J Climatol 14:964-978

Hawkins DM (1977) Testing a sequence of observations for a shift in location. J Am Stat Assoc 72:180-186

Hirsch RM, Slack JR, Smith RA (1982) Techniques of trend analysis for monthly water quality data. Water Resour Res 1:107-121

IPCC (2002) Climate change and biodiversity: IPCC Technical Paper V. https://www.ipcc.ch/pdf/technicalpapers/climate-changes-biodiversity-en.pdf

IPCC (2007) The physical science basis, contribution of working group I, II and III ti the Third assessment report of IPCC, eds. Saloman S, Qin D, Manning M, Chan Z, Marquis M, Averyt KS, Tignor M, Miller HL. Cambridge Uni Press, UK and NY, USA: 966 pp

Jain SK, Kumar V (2012) Trend analysis of rainfall and temperature data for India. Curr Sci 102(1):37-49

Jaiswal AK, Prakasa Rao GS, De US (2008) Spatial and temporal characteristics of evaporation trends over India during 1971-2000. Mausam 59(2):149-158

Kahya E, Kalayci S (2004) Trend analysis of streamflow in Turkey. J Hydrol 289:128-144

Kang HF, Yusof F (2012) Homogenity test on daily rainfall series in Peninsular Malasiya. Int J Contemp Math Sci 7(1):9-22

Karmeshu N (2012) Trend Detection in Annual Temperature and Precipitation using the Mann Kendall Test—A Case Study to Assess Climate Change on Select States in the Northeastern United States. Master of Environment Studies Capstone project, University of Pennsylvania USA, http://repository.upenn.edu/mes_ capstones/47

Karpouzos DK, Kavalieratou S, Babajimopoulos C (2010) Trend analysis of precipitation data in Pieria Region (Greece). Eur Water 30:31-40

Katiraie P, Hajjam H, Irannejad P (2007) Contribution from the variations of precipitation frequency and daily intensity to the precipitation trend in Iran over the period 1960-2001. J Earth Space Phys 33(1):22

Kim HJ, Siegmund D (1989) The likelihood ratio test for a change-point in simple linear regression. Biometrika 76:409-423

Lettenmaier DP (1976) Detection of trends in water quality data from records with dependent observations. Water Resour Res 12(5):1037-1046

Levin N (2011) Climate-driven changes in tropical cyclone intensity shape dune activity on Earth's largest sand island. Geomorphology 125:239-252. doi:10.1016/j.geomorph.2010.09.021

Li S, Lund RB (2012) Multiple change point detection via genetic algorithms. J Clim 25:674-686

Lugina KM, Groisman PY, Vinnikov KY, Koknaeva VV, Speranskaya NA (2006) Monthly surface air temperature time series area-averaged over the 30-degree latitudinal belts of the globe, 1881-2005 in Trends: A Compendium of Data on Global Change. Carbon Dioxide Information Analysis Center, Oak Ridge National Laboratory, US Department of Energy, Oak Ridge, USA doi: 10.3334/CDIAC/cli.003

Lund RB, Reeves J (2002) Detection of undocumented change points: a revision of the two-phase regression model. J Clim 15:2547-2554

Marengo JA, Camargo CC (2008) Surface air temperature trends in southern Brazil for 1960-2002. Int J Climatol 28:893-904. doi:10.1002/joc. 1584

Mauget SA (2003) Intra to multi-decadal climate variability over the continental United States. Int J Climatol 16: 2215-2231. doi:10.1175/2751.1

Mavromatis T, Stathis D (2011) Response of the water balance in Greece to temperature and precipitation trends. Theor Appl Climatol. doi:10.1007/s00704-010-0320-9

Menne JM, Williams CNJ (2005) Detection of undocumented change points using multiple test statistics and composite reference series. J Clim 18:4271-4286

Mitchell JM, Dzezerdzeeskii B, Flohn H, Hofmeyer WL, Lamb HH, Rao KN, Wallen CC (1996) Climatic change. WMO Technical Note 79, WMO No. 195.TP-100, Geneva 79 pp 
Modarres R, Da Silva V (2007) Rainfall trends in arid and semi-arid regions of Iran. J Arid Environ 70:344-355

Mu X, Zhang L, McVicar TR, Chille B, Gau P (2007) Analysis of the impact of conservation measures on stream flow regime in catchments of the Loess Plateau, China. Hydrol Process 21:2124-2134

Owen DB (1962) Handbook of statistical tables. Addison-Wesley Publishing Company, Massaschusetts

Partal T, Kahya E (2006) Trend analysis in Turkish precipitation data. Hydrol Process 20:2011-2026

Pettitt AN (1979) A non-parametric approach to the change point problem. J Appl Stat 28(2):126-135

Portnyagin YI, Merzlyakov EG, Solovjova TV, Jacobi C, Kurschner D, Manson A, Meek C (2006) Long-term trends and year-to-year variability of mid-latitude mesosphere/lower thermosphere winds. J Atmos Solut Terr Phys 68:1890-1901. doi:10.1016/j.jastp.2006.04.004

Radziejewski M, Bardossy A, Kundzewicz ZW (2000) Detection of change in river flow using phase randomization. Hydrol Sci J 45(4):547-558

Ravindran PN, Nirmal Babu K, Sasikumar B, Krishnamurthy KS (2000) Botany and Crop Improvement of Black pepper. (in) Black pepper pp 23142 (Eds.) Ravindran P N. Harwood academic publishers

Rodionov SN (2004) A sequential algorithm for testing climate regime shifts. Geophys Res Lett 31:L09204. doi: 10.1029/2004GL019448

Roshan GH, Khoshakh LF, Azizi G, Mohammadi H (2011) Simulation of temperature changes in Iran under the atmosphere carbon dioxide duplication condition. Iran J Environ Health Sci Eng 8:139-152

Sabohi R (2009) Trend analysis of climatic factors in great cities of Iran. Int J Clim Chang 18:34-43

Sadmani M, Safar M, Roknian M (2012) Trend analysis in reference evaporation using Mann Kendall and Spearman' rho test in arid regions of Iran. Water Resour Manag 26(1):211-224

Salarijazi M, Ali Mohammad AA, Adib A, Daneshkhan A (2012) Trend and change-point detection for the annual stream-flow series of the Karun River at the Ahvaz hydrometric station. Afr J Agric Reserv 7(32): $4540-4552$

Schaefer D, Domroes M (2009) Recent climate change in Japan-Spational and temporal characteristics of trends of temperature. Clim Past 5:13-19

Seidel DJ, Lanzante JR (2004) As assessment of three alternatives to linear trends for characterizing global atmospheric temperature changes. J Geophys Res 109:D14108. doi:10.1029/2003JD004414

Serra C, Burgueno A, Lana X (2001) Analysis of maximum and minimum daily temperatures recorded at Fabra observatory (Barcelona, NE Spain) in the period 1917-1998. J Clim 21:617-636

Shirgholami H, Ghahraman B (2009) Study of time trend changes in annual mean temperature of Iran. J Sci Technol Agric Nat Resour 23:44-53

Shrestha S, Khatiwada M, Babel MS, Parajuli K (2014) Impact of climate change on hydropower in Kulekhani hydropower project in Nepal. Environ Process 1(3):231-250

Silvestrini A, Veredas D (2008) Temporal aggregation of univariate and multivariate time series model: a survey. J Econ Survey 22(3):458-497

Sivakumar T, Thennarasu A, Rajkumar JSI (2012a) Effect of season on the incidence of infectious diseases of bovine in Tamilnadu. Elixir Meteorol 47:8874-8875

Sivakumar T, Thennarasu A, Rajkumar JSI (2012b) Trend analysis of the climatic parameters (2001-2007) for the northeastern zone of Tamilnadu. Int J Res Environ Sci Technol 2(3):83-86

Smadi MM (2006) Observed abrupt changes in minimum and maximum temperatures in Jordan in the 20th century. Am J Environ Sci 2(3):114-120

Smadi MM, Zghoul A (2006) A Sudden Change in Rainfall characteristics in Amman, Jordan during the Mid 1950's. Am J Environ Sci 2(3):84-91

Sneyers S (1990) On the statistical analysis of series of observations. Technical note no 5 143, WMO No 725415 Secretariat of the World Meteorological Organization, Geneva, $192 \mathrm{pp}$

Staudt M, Esteban-Parra, Castro-Diez Y (2007) Homogenization of long-term monthly Spanish temperature data. Int J Climatol 27:1809-1823. doi:10.1002/joc.1493

Stepanek P, Zahradnek P, Skalak P (2009) Data quality control and homogenization of air temperature and precipitation series in the area of Czech Republic in the period of 1961-2007. Int J Global Energy. doi:10. 1504/IJGGI.2009.030657

Su BD, Jiang T, Jin WB (2006) Recent trends in observed temperature and precipitation extremes in the Yangtze river basin, China. Theor Appl Climatol 83:139-151. doi:10.1007/s00704-005-0139-y

Sun H, Chen Y, Li W, Li F, Chen Y, Hao X, Yang Y (2010) Variation and abrupt change of climate in Ili River Basin, Xinjiang. J Geogr Sci 20(5):652-666

Sweitzer TA, Kolaz DJ (1984) An assessment of the influence of meteorology on the trend of ozone concentrations in the Chicago area. Conf Quality Assurance in Air Pollu Measure, Boulder, Colorado

Tabari H, Marofi S (2011) Changes of pan evaporation in the west of Iran. Water Resour Manag 25:97-111

Tabari H, Marofi S, Aeini A, Talaee PH, Mohammadi K (2011) Trend analysis of reference evapotranspiration in the western half of Iran. Agric Forest Meteorol 151:128-136

Tarhule A, Woo M (1998) Changes in rainfall characteristics in northern Nigeria. Int J Climatol 18:1261-1271 
Tomé AR, Miranda PMA (2004) Piecewise linear fitting and trend changing points of climate parameters. Geophys Res Lett 31:L02207. doi:10.1029/2003GL019100

Tu JY, Chou C, Chu PS (2009) The abrupt shift of typhoon activity in the vicinity of Taiwan and its association with western north Pacific-East Asian climate change. J Clim 22:3617-3628. doi:10.1175/2009JCLI2411.1

Verstraeten G, Poesen J, Demarée G, Salles C (2006) Long-term (105 years) variability in rain erosivity as derived from 10-min rainfall depth data for Ukkel (Brussels, Belgium): implications for assessing soil erosion rates. J Geophys Res 111:1-11

Vezzoli R, Pecora S, Zenoni E, Tonneli F (2012) Inhomogeneity, change points, trends in observations: an application to Po river discharge extremes. Centre Euro-Mediterraneo Sui Combiamenti Climatici (CMCC) Research Paper RP0138:1-15

Winingaard JB, Kleink Tank AMG, Konnen GP (2003) Homogeneity of 20th Century European Daily Temperature and Precipitation Series. Int J Climatol 23:679-692

World Meteorological Organization (1966) Climate change, World Meteorological Organization, Technical Note 79. Geneva

Yu PS, Yang TC, Kuo CC (2006) Evaluating long-term trends in annual and seasonal precipitation in Taiwan. Water Resour Manag 20:1007-1023. doi:10.1007/s11269-006-9020-8

Yue S, Hashino M (2003) Long term trends of annual and monthly precipitation in Japan. J Am Water Resour 39(3):587-596

Yue S, Pilon P (2004) A comparison of the power of the $t$ test, Mann-Kendall and bootstrap tests for trend detection. Hydrol Sci J 49(1):21-37

Yue S, Wang C (2004) The Mann-Kendall Test Modified by Effective Sample Size to Detect Trend in Serially Correlated Hydrological Series. Water Resour Manag 18:201-218

Yue S, Pilon P, Cavadias G (2002) Power of the Mann-Kendall and Spearman's rho tests for detecting monotonic trends in hydrological series. J Hydrol 259:254-271

Yue S, Pilon P, Phinney B (2003) Canadian stream-flow trend detection: impacts of serial and cross-correlation. Hydrol Sci J 48(1):51-63

Zer Lin W, Chung TH, Ho WC, Hsien TW (2005) Urbanization-induced regional climate change on the western plain of Taiwan for the period 1964-1999; Int Conf Environ, Ecosys and Develop, Venice, Italy

Zhang S, Lu XX (2009) Hydrological responses to precipitation variation and diverse human activities in a mountainous tributary of the lower Xijiang, China. Catena 77:130-142

Zhao X, Chu PS (2010) Bayesian changepoint analysis for extreme events (typhoons, heavy rainfall, and heat waves): an RJMCMC approach. J Clim 23:1034-1046. doi:10.1175/2009JCLI2597.1 